\title{
Endovascular Thrombectomy of Calcified Emboli in Acute Ischemic Stroke: A Multicenter Study
}

(D).J. Maurer, (D). Dobrocky, (D) J. Joachimski, (D). Neuberger, (D)T. Demerath, (D)A. Brehm, (D) A. Cianfoni, (D) B. Gory, (D)A. Berlis, (D). Gralla, (D).A. Möhlenbruch, (D) K.A. Blackham, (D) M.N. Psychogios, DP. Zickler, and (D). Fischer

\section{ABSTRACT}

BACKGROUND AND PURPOSE: Large intracranial vessel occlusion due to calcified emboli is a rare cause of major stroke. We assessed the prevalence, imaging appearance, the effectiveness of mechanical thrombectomy, and clinical outcome of patients with large-vessel occlusion due to calcified emboli.

MATERIALS AND METHODS: We performed a retrospective analysis of clinical and procedural data of consecutive patients who underwent mechanical thrombectomy due to calcified emboli in 7 European stroke centers.

RESULTS: We screened 2969 patients, and 40 patients matched the inclusion criteria, accounting for a prevalence of 1.3\%. The mean maximal density of the thrombus was $327 \mathrm{HU}$ (range, 150-1200 HU), and the mean thrombus length was $9.2 \mathrm{~mm}$ (range, 4$20 \mathrm{~mm}$ ). Four patients had multiple calcified emboli, and 2 patients had an embolic event during an endovascular intervention. A modified $\mathrm{TICl}$ score of $\geq 2 \mathrm{~b}$ was achieved in $57.5 \%$ (23/40), with minimal-to-no reperfusion (modified $\mathrm{TICI} 0-1$ ) in $32.5 \%$ (13/40) and incomplete reperfusion (modified $\mathrm{TICl} 2 \mathrm{a}$ ) in 10\% (4/40). Excellent outcome (mRS 0-1) was achieved in only 20.6\%, functional independence (mRS $0-2$ ) in $26.5 \%$ and 90 -day mortality was $55.9 \%$.

CONCLUSIONS: Acute ischemic stroke with large-vessel occlusion due to calcified emboli is a rare entity in patients undergoing thrombectomy, with considerably worse angiographic outcome and a higher mortality compared with patients with noncalcified thrombi. Good functional recovery at 3 months can still be achieved in about a quarter of patients.

ABBREVIATIONS: CLASS = calcium load assessment; $\mathrm{MT}=$ mechanical thrombectomy; $\mathrm{mTICI}=$ modified TICI

alcified emboli are a rare, underreported cause of ischemic stroke. ${ }^{1}$ Their prevalence has been estimated as between $2.7 \%$ and $5.9 \%$ of all patients presenting with acute ischemic stroke. ${ }^{1,2}$ Intravenous rtPA seems to be an ineffective treatment, probably due to the thrombus composition. ${ }^{3}$ Endovascular

Received October 5, 2019; accepted after revision December 23.

From the Departments of Diagnostic and Interventional Radiology and Neuroradiology (C.J.M., F.J., A.Berlis) and Neurology and Neurophysiology (P.Z.), Universitätsklinikum Augsburg, Augsburg, Germany; University Institute of Diagnostic and Interventional Neuroradiology (T.Dobrocky, J.G.), University of Bern, Inselspital, Bern, Switzerland; Department of Neuroradiology (U.N., M.A.M.) University of Heidelberg, Heidelberg, Germany; Department of Neuroradiology (T.Demerath, A.Brehm, K.A.B., M.N.P.), Clinic of Radiology and Nuclear Medicine, University Hospital Basel, Basel, Switzerland; Department of Neuroradiology (A.Brehm, M.N.P.), University Medical Center Göttingen, Göttingen, Germany; Department of Neuroradiology (A.C.), Neurocenter of Southern Switzerland, Lugano, Switzerland; Department of Diagnostic and Therapeutic Neuroradiology (B.G.), University Hospital of Nancy, Institut National de la Santé et de la Recherche Médicale U1254, Nancy, France; and Institut für Diagnostische und Interventionelle Radiologie, Neuroradiologie (S.F.), Nuklearmedizin,

Knappschaftskrankenhaus Bochum-Langendreer, Universitätsklinik, Bochum, Germany.

Please address correspondence to Christoph J. Maurer, MD, Departments of Diagnostic and Interventional Radiology and Neuroradiology, Universitätsklinikum Augsburg, Stenglinstraße 2, 85221 Augsburg, Germany; e-mail:

Christoph.Maurer@uk-augsburg.de; @Podaleirios5

http://dx.doi.org/10.3174/ajnr.A6412 therapy has been suggested as an alternative. ${ }^{4}$ There are several case reports and case series describing endovascular treatment of calcified cerebral emboli ${ }^{4-11}$ with low recanalization rates, but due to the small number of patients, no definite recommendation has been reported. In this study, we, therefore, aimed to assess the prevalence, angiographic outcome, and treatment effects of cerebral calcified emboli in large-vessel occlusion treated by an endovascular approach in a large multicenter cohort.

\section{MATERIALS AND METHODS Patient Demographics}

This study was approved by the ethics review board of our institution and was conducted according to the principles of the Declaration of Helsinki. Due to the retrospective character of the data collection and analysis, written informed consent was waived. The data supporting the findings of this study are available from the corresponding author, upon reasonable request.

In this retrospective multicenter study, we analyzed data prospectively collected from patients with acute ischemic stroke who met the following inclusion criteria: Intracranial thrombectomy 
was performed, and intracranial large-vessel occlusion due to a calcified embolus was diagnosed on unenhanced CT. A calcified embolus was defined as an oblong, not circular or semicircular, calcification with clearly intraluminal localization on CT angiography at the site of intracranial vessel occlusion. An ROI was drawn over the hyperdense thrombus, and the Hounsfield units were measured to identify emboli with a calcific component. Analogous to cardiology scoring systems, calcification was defined by a density of at least $130 \mathrm{HU}$ on unenhanced CT. ${ }^{12}$ Only definite cases of calcified emboli were included. Further patient work-up, including multitechnique diagnostic imaging and treatment, was performed according to international guidelines. ${ }^{13}$ All 7 participating comprehensive stroke centers are highvolume facilities and offer interventional stroke treatment 24/7 with long-time experience in endovascular thrombectomy. ${ }^{14}$

\section{Outcome}

We obtained demographic and clinical data, including the NIHSS score and mRS on admission, discharge, and after 90 days, if available, and the presence of cardiovascular risk factors. Time metrics were evaluated, including the time of symptom onset, hospital admission, first imaging, groin puncture, and recanalization. Imaging data included the ASPECTS on admission and after 24 hours, intracranial hemorrhage classified according to the European Cooperative Stroke Study (ECASS), ${ }^{15}$ thrombus localization, length and density together with the presumed source of the embolus, and the existence of multiple calcified emboli and concomitant extracranial stenosis. Additionally, procedural data were gathered, including materials, medication during the procedure, number of passes, complications, and angiographic outcome using the modified TICI (mTICI) classification. ${ }^{16}$

To estimate the extent of atherosclerosis-associated calcification as a potential source of calcified emboli, we developed a simple qualitative scoring system termed the calcium load assessment (CLASS) score, scoring the following regions, if available, on CT angiographic images: mitral valve, aortic valve, aortic arch, brachiocephalic artery, carotid bifurcation, and vertebral artery. For the carotid bifurcation and the vertebral artery, the more severely affected side was evaluated. The calcium load at each region was classified into 0 (none), 1 (mild), 2 (moderate), and 3 (extensive). The overall CLASS score was calculated by adding the scores for each available region and then dividing the sum by the number of available regions, with a potential score ranging from 0 to 3 .

\section{Statistical Analysis}

Statistical analyses were performed with R, Version 3.5.3 (http:// www.r-project.org/). Baseline characteristics are presented as frequencies, mean with $\mathrm{SD}$, or median and interquartile range. Univariate analyses comparing demographic- and interventionrelated variables that were potentially relevant for predicting the clinical outcome and recanalization were performed.

\section{RESULTS}

\section{Patient Characteristics}

In 7 European stroke centers in Germany, Switzerland, and France, a total of 2969 patients who underwent mechanical thrombectomy
Table 1: Baseline patient characteristics $(n=40)$

\begin{tabular}{lc}
\hline \multicolumn{2}{c}{ Characteristics } \\
\hline Demographic data and medical history \\
Age (mean) (yr) & $78 \pm 9.6$ \\
Female sex & $68 \%(27 / 40)$ \\
Current smoker & $8 \%(3 / 38)$ \\
Hypertension & $74 \%(28 / 38)$ \\
Diabetes mellitus & $39 \%(15 / 38)$ \\
Hypercholesterolemia & $41 \%(15 / 37)$ \\
Baseline NIHSS (mean) & $15.4 \pm 7.2$ \\
Pretreatment ASPECTS & \\
0-5 & $5.1 \%(2 / 39)$ \\
6-10 & $94.9 \%(37 / 39)$ \\
IV thrombolysis & $47.5 \%(19 / 40)$ \\
\hline
\end{tabular}

(MT) were retrospectively screened. Forty patients matched the inclusion criteria, accounting for a prevalence of $1.3 \%$ in patients having undergone MT. The mean age was $77.9 \pm 9.6$ years (range, $56-100$ years); $68 \%$ were women. The baseline patient characteristics are presented in Table 1.

The mean NIHSS on admission was $15.4 \pm 7.2$; the median, 14 ; and the interquartile range, $11-20$. The median initial ASPECTS was 9 (interquartile range, $7-9$ ); $47.5 \%$ of patients received IV rtPA before the intervention.

\section{Occlusion Site and Clot Description}

Clot location in most patients was in the middle cerebral artery, with $65 \%$ in the M1 segment and 12.5\% in the M2 segment; $15 \%$ had a calcified clot in the carotid T, and 7.5\%, in the basilar artery. A dual pathology with additional extracranial stenosis in the ipsilateral ICA requiring treatment was found in 2 patients (5\%). In both cases, extensive calcification of the bifurcation was reported.

The mean maximal density of the thrombus was $327 \mathrm{HU}$ (range, 150-1200 $\mathrm{HU}$ ), and the mean thrombus length was $9.2 \mathrm{~mm}$ (range, 4-20 mm). The presumed source of embolization was unknown in $37.5 \%(15 / 40)$, cardiac in $17.5 \%(7 / 40)$, aortic arch in $15 \%(6 / 40)$, and ICA in $30 \%(12 / 40)$. Four patients had multiple calcified emboli, and 2 patients had an embolic event during an endovascular intervention (transcatheter aortic valve implantation and repair of an infrarenal aortic aneurysm). Extracranial calcification was most prominent at the carotid bifurcation and the aortic arch. The mean CLASS score was 1.1 (range, $0-2.5$ ). Table 2 summarizes the occlusion site and clot properties. The Figure gives examples of intracranial calcified clots.

\section{Procedural Characteristics and Clinical Outcome}

The mean duration of the procedure was 93 minutes, ranging from 23 to 250 minutes. A balloon-guide catheter was used in $15 \%(6 / 40)$. Distal aspiration alone or stent retrieval alone was performed in 5\%, respectively. The preferred recanalization method was a combination of stent retrieval and distal aspiration in $90 \%(36 / 40)$. The number of retrieving maneuvers ranged from 1 to 7 , with a mean value of 2.7. Successful recanalization after 1 pass was achieved in 12 cases (30\%), with a combination of distal aspiration and stent retrieval in 9 cases, distal aspiration alone in 2 cases, and stent retrieval alone in 1 case. Extracranial stent placement at the ICA bifurcation was performed in only 1 patient (2.5\%); percutaneous transarterial angioplasty of the extracranial stenosis, in 2 patients (5\%); and intracranial stent 
placement after failed thrombectomy, in 2 patients (5\%). An mTICI score of $\geq 2 \mathrm{~b}$ was achieved in $57.5 \%$ (23/40), with mTICI $2 \mathrm{~b}$ in $32.5 \%$ and mTICI 3 in 25\%. Minimal-to-no reperfusion (mTICI 0-1) was reported in 32.5\% (13/40); and incomplete reperfusion (mTICI 2a), in $10 \%(4 / 40)$. For 9 of the 13 patients with minimal-to-no reperfusion, 3-month follow-up was available with an mRS of 6 in 8/9 (89\%) patients and mRS of 1 in 1/9 (11\%) patients. The procedural data are summarized in Table 3; clinical outcome, in Table 4.

Procedural complications were reported in 4 patients. Two patients had a vessel perforation in a lenticulostriate branch and in M3, respectively. In 1 case, the pusher wire of the stent retriever broke and had to be left in the vessel without recanalization. One patient had nasopharyngeal bleeding, most probably due to IV thrombolysis. Symptomatic hemorrhage occurred in $5.3 \%$ (2/40); only 1 of these 2 patients had received IV rtPA. The ASPECTS 24 hours after treatment ranged from 0 to 10 , with a median of 5. Ninety-day clinical outcome was available in 34 patients. Excellent outcome (mRS 0-1) was achieved in only $20.1 \%$ (7/34); functional independence (mRS $0-2$ ), in $26.5 \%$ (9/34); and 90-day mortality was 55.9\% (19/34).

Table 2: Clot location and characteristics $(n=40)$

\begin{tabular}{lc}
\hline \multicolumn{1}{c}{ Characteristics } \\
\hline Clot location (parent vessel) \\
Right anterior circulation & $55 \%(22 / 40)$ \\
Left anterior circulation & $37.5 \%(15 / 40)$ \\
Posterior circulation & $7.5 \%(3 / 40)$ \\
Clot location & \\
M1 & $65 \%(26 / 40)$ \\
M2 & $12.5 \%(5 / 40)$ \\
Carotid T & $15 \%(6 / 40)$ \\
Basilar artery & $7.5 \%(3 / 40)$ \\
Tandem pathology & $10 \%(4 / 40)$ \\
Thrombus characteristics & \\
Maximal density (mean) (HU) & $327 \pm 202$ \\
Length (mean) (mm) & $9.2 \pm 4.3$ \\
Multiple emboli & $10 \%(4 / 40)$ \\
CLASS score (mean) & $1.1 \pm 0.7$ \\
Range of CLASS score & $0-2.5$ \\
Spontaneous embolization & $95 \%(38 / 40)$ \\
Embolization during endovascular treatment & $5 \%(2 / 40)$ \\
\hline
\end{tabular}

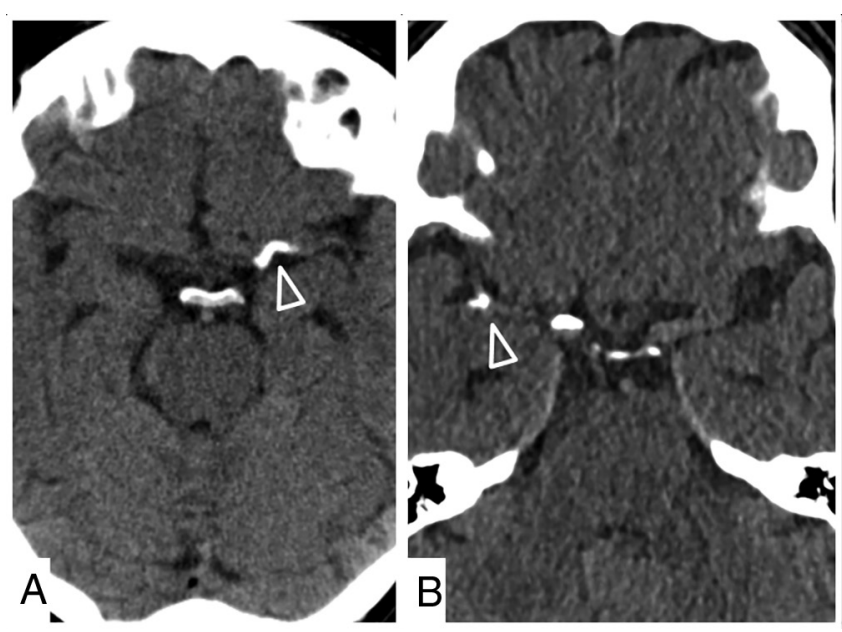

In univariate analysis using a dichotomized mRS at discharge or at 3 months, no parameter correlated with good outcome. A multivariate analysis was not feasible due to the small sample size.

\section{DISCUSSION}

A high intracranial calcification burden has been proposed as a marker of worse clinical outcome in patients with occlusion of the middle cerebral artery. ${ }^{17}$ Thrombus density on unenhanced $\mathrm{CT}$, on the other hand, has been discussed as a potential predictor of successful recanalization, ${ }^{18}$ though available data are equivocal. ${ }^{19}$ In most publications, no distinction is made between red blood cell-rich thrombi with a hyperdense appearance on CT and truly calcified emboli, probably due to the rare occurrence and reporting of the phenomenon. In our analysis, we clearly discriminated the 2 entities via imaging criteria and thus provided the most comprehensive analysis of this subtype of stroke and its endovascular therapy so far. In our patients, good angiographic outcome ( $\mathrm{mTICI} \geq 2 \mathrm{~b}$ ) was achieved in $57.5 \%$, which is comparable with the results of the MR CLEAN trial with a modified TICI score of $2 \mathrm{~b}$ and 3 in $58.7 \% .^{20}$ The pooled data of the Highly Effective Reperfusion Evaluated in Multiple Endovascular Stroke (HERMES) Trial collaborators, however, showed a good angiographic outcome in $71 \%{ }^{21}$ Other real-world data of mechanical thrombectomy with aspiration, stent retrieval, or combined approaches demonstrate angiographic results with mTICI scores of $2 \mathrm{~b}$ or 3 in $65 \%-93 \%,{ }^{22,23}$ depending on the thrombectomy technique. Compared with these data, the recanalization rate in our series with calcified emboli is clearly on the lower end of the range. A potential reason might be distinct friction properties of hard calcified clots, which could lead to less adhesion to the stent retriever during mechanical thrombectomy. ${ }^{24}$

In our series, intracranial stent placement was performed in only 2 patients after 4 and 5 unsuccessful thrombectomy maneuvers, respectively. There are only limited data on intracranial stent placement after unsuccessful thrombectomy $y^{25,26}$ and on stent placement as a primary treatment of intracranial occlusion in acute stroke in the pre-stent-retriever era. ${ }^{27-29}$ Successful recanalization with primary intracranial stent placement (mTICI $2 \mathrm{~b}-3$ or Thrombolysis in Myocardial Infarction 2-3) is reported in $65 \%-100 \%$ of patients

FIGURE. Examples of calcified emboli (arrowheads) in the left M1 (A), right middle cerebral artery bifurcation (B), left $\mathrm{M} 2(C)$, and carotid T (D). 
Table 3: Procedural characteristics

\begin{tabular}{lc}
\hline \multicolumn{1}{c}{ Characteristics } \\
\hline Unknown onset \\
Known onset to recanalization $(n=27 / 40)$ \\
$\quad$ (mean) (min) \\
Procedural time (mean) (min) \\
No. of passes (mean) & $32.5 \%(13 / 40)$ \\
Range & $93 \pm 216$ \\
Aspiration alone & $2.7 \pm 1.7$ \\
Stent retrieval alone & $1-7$ \\
Combination (stent retrieval and aspiration) & $5 \%(2 / 40)$ \\
Additional intracranial stent placement & $5 \%(2 / 40)$ \\
Angiographic results & $90 \%(36 / 40)$ \\
$\quad$ mTICI 0 & $5 \%(2 / 40)$ \\
$\quad$ mTICI 1 & \\
$\quad$ mTICI 2a & $25 \%(10 / 40)$ \\
mTICI 2b & $7.5 \%(3 / 40)$ \\
mTICI 3 & $10 \%(4 / 40)$ \\
Successful recanalization after 1 pass & $32.5 \%(13 / 40)$ \\
IV heparin & $25 \%(10 / 40)$ \\
IV ASA & $30 \%(12 / 40)$ \\
IA rtPA & $35 \%(14 / 40)$ \\
\hline
\end{tabular}

Note:-ASA indicates acetylsalicylic acid; IA, intra-arterial.

Table 4: Clinical outcome

\begin{tabular}{lc}
\hline \multicolumn{1}{c}{ Outcome } \\
\hline Parenchymal hematoma type 1 and 2 & $7.5 \%(3 / 40)$ \\
Symptomatic hemorrhage & $5.3 \%(2 / 38)$ \\
$90-D a y$ mRS available & $85 \%(34 / 40)$ \\
0 & $2.9 \%(1 / 34)$ \\
1 & $17.1 \%(6 / 34)$ \\
2 & $5.9 \%(2 / 34)$ \\
3 & $5.9 \%(2 / 34)$ \\
4 & $0 \%(0 / 34)$ \\
5 & $11.8 \%(4 / 34)$ \\
6 & $55.9 \%(19 / 34)$ \\
\hline
\end{tabular}

and good clinical outcome after 30-90 days (mRS $\leq 2$ ) in 40\%-50\% of patients. Thus, early intracranial stent placement after failed thrombectomy might be an option in patients with calcified thrombi. In our patients, however, stent placement as a last resort did not lead to good outcomes in either patient.

In our cohort, good clinical outcome after 90 days with an mRS of $\leq 2$ was achieved in only $26.4 \%$, compared with $46 \%$ in the HERMES data and 55.3\% in the Trevo Registry. ${ }^{23}$ A 55.9\% mortality rate at 90 days in our cohort was dismal compared with $15.3 \%$ reported by the HERMES collaborators and $13.9 \%$ by the Trevo Registry. A potential reason for the worse clinical outcome in our cohort might be the older patient age, with a mean age of 78 years compared with 68 years in the HERMES data and Trevo Registry, though age does not seem to be associated with lower recanalization rates in patients with acute ischemic stroke undergoing endovascular therapy. ${ }^{30,31}$ In a recent meta-analysis that included HERMES data, only $27 \%$ of patients 80 years of age or older achieved a good functional outcome, while $34 \%$ of patients died. ${ }^{32}$ Successful recanalization was achieved in $78 \%$ in this analysis in contrast to $58 \%$ in our cohort. The combination of lower recanalization rates and patient age may explain the higher mortality in our group.

The extent of arteriosclerosis as measured with the CLASS score did not correlate with procedural time, number of passes, and angiographic or clinical outcome. Surprisingly, there was no significant correlation between procedural time or the number of passes and outcome, though this was probably due to the small sample size.

In our patient population, the administration of IV rtPA did not lead to a better outcome or to a higher complication rate. The dissolution of calcification within an embolus by rtPA is unlikely. ${ }^{33}$ The calcified material, however, could be associated with fibrin-rich thrombus and thus respond to $\mathrm{rtPA}^{34}$ Therefore, the complete rejection of rtPA for calcified emboli cannot be recommended on the basis of our data.

There are several limitations to our study. First, this was a retrospective analysis during 6 years with only a limited number of patients, yet it represents the largest cohort of patients undergoing thrombectomy due to calcified thrombi to date. Statistical analysis, however, is severely limited due to the small sample size, and we have no histopathologic data due to the retrospective nature of this study. Additionally, we included only definite cases of calcified emboli. Because there is an obvious overlap with intracranial atherosclerotic disease due to the calcific components, the number of unreported cases might be even higher. Furthermore, no information is available on patients with calcified emboli and large-artery occlusion not undergoing thrombectomy, so the outcome of all patients with calcified emboli-treated or not-might be even worse. Second, a control group is lacking, and the recanalization rates and clinical outcome can be compared with only similar published cohorts. Third, our study had a multicenter design with different logistic and procedural standards in each institution. Nevertheless, the thrombectomy strategy was similar in all institutions, with a combination of stent retrieval and large-bore distal aspiration catheter as a first-line approach.

\section{CONCLUSIONS}

Acute ischemic stroke with large-vessel occlusion due to calcified emboli is a rare entity in patients undergoing thrombectomy, with a higher age on average. These patients have a considerably worse angiographic outcome and a higher mortality rate compared with patients with noncalcified thrombi. Good functional outcome can be expected in approximately 1 in 4 patients.

Disclosures: Christoph J. Maurer-UNRELATED: Grants/Grants Pending: MicroVention, Stryker, Comments: educational grants. Ansgar Berlis-UNRELATED: Consultancy: proctoring MicroVention, Stryker, Medtronic; Payment for Lectures Including Service on Speakers Bureaus: Penumbra; Other: Clinical Ethics Committee phenox, Comments: Money paid to the individual. Jan Gralla-RELATED: Grant: Medtronic, Comments: Global Principal Investigator of the Swift Direct Study*; Fees for Participation in Review Activities Such as Data Monitoring Boards, Statistical Analysis, Endpoint Committees, and the Like: Penumbra, Comments: CEC of the Promise Study*; UNRELATED: Grants/Grants Pending: Schweizerischer Nationalfonds, Comments: MRI in stroke.* Markus A. Möhlenbruch-UNRELATED: Consultancy: Medtronic, MicroVention, Stryker; Grants/Grants Pending: Balt, MicroVention*; Payment for Lectures Including Service on Speakers Bureaus: Medtronic, MicroVention, Stryker. Kristine A. Blackham—UNRELATED: Consultancy: Medtronic.* Philipp Zickler-UNRELATED: Consultancy: Boehringer-Ingelheim; Payment for Lectures Including Service on Speakers Bureaus: Bristol-Myers-Squibb; Travel/Accommodations/Meeting Expenses Unrelated to Activities Listed: Bayer AG, Daiichi Sankyo. Sebastian Fischer-UNRELATED: Consultancy: MicroVention, phenox, Kaneka, Stryker.* *Money paid to the institution.

\section{REFERENCES}

1. Walker BS, Shah LM, Osborn AG. Calcified cerebral emboli, a "do not miss" imaging diagnosis: 22 new cases and review of the literature. AJNR Am J Neuroradiol 2014;35:1515-19 CrossRef Medline 
2. Bardon M, Hanson J, O'Brien B, et al. Calcified cerebral emboli: incidence and implications. J Med Imaging Radiat Oncol 2018 Apr 17. [Epub ahead of print] CrossRef Medline

3. Halloran JI, Bekavac I. Unsuccessful tissue plasminogen activator treatment of acute stroke caused by a calcific embolus. J Neuroimaging 2004;14:385-87 CrossRef Medline

4. Raghib MF, Mutzenbach JS, Rösler C, et al. Acute treatment of stroke due to spontaneous calcified cerebral emboli causing large vessel occlusion. J Clin Neurosci 2018;47:56-61 CrossRef Medline

5. Schirmer CM, Thaler DE, Malek AM. Stent-mediated wedging of a calcific embolus to recanalize an occluded middle cerebral artery: technical case report. Neurosurgery 2008;63:E180-81; discussion E181 CrossRef Medline

6. Uneda A, Kanda T, Suzuki K, et al. Acute cerebral artery occlusion by a calcified embolus with false patency sign on computed tomographic angiography. J Stroke Cerebrovasc Dis 2017;26:e5-7 CrossRef Medline

7. Ramírez-Moreno JM, Trinidad-Ruiz M, Ceberino D, et al. Trombectomía mecánica en un ictus isquémico debido a embolia cerebral cálcica. Neurologia 2017;32:270-73 CrossRef Medline

8. Koh E, Kwak HS, Chung GH. Manual aspiration thrombectomy in patients with acute stroke-related calcified cerebral emboli. J Stroke Cerebrovasc Dis 2017;26:2050-54 CrossRef Medline

9. Kwak HS, Park JS. Successful recanalization using the Embolus Retriever with Interlinked Cage for acute stroke due to calcified cerebral emboli. Interv Neuroradiol 2018;24:674-77 CrossRef Medline

10. Dobrocky T, Piechowiak E, Cianfoni A, et al. Thrombectomy of calcified emboli in stroke: does histology of thrombi influence the effectiveness of thrombectomy? J Neurointerv Surg 2018;10:345-50 CrossRef Medline

11. Yogendrakumar V, Patro S, Dowlatshahi D, et al. Calcified embolus mimics patent middle cerebral artery on CT angiogram. Pract Neurol 2017;17:307-09 CrossRef Medline

12. Agatston AS, Janowitz WR, Hildner FJ, et al. Quantification of coronary artery calcium using ultrafast computed tomography. $\mathrm{J} \mathrm{Am}$ Coll Cardiol 1990;15:827-32 CrossRef Medline

13. Ahmed N, Steiner T, Caso V, et al; ESO-KSU session participants. Recommendations from the ESO-Karolinska Stroke Update Conference, Stockholm 13-15 November 2016. Eur Stroke J 2017; 2:95-102 CrossRef Medline

14. Pierot L, Jayaraman MV, Szikora I, et al; Asian-Australian Federation of Interventional and Therapeutic Neuroradiology (AAFITN), Australian and New Zealand Society of Neuroradiology (ANZSNR), American Society of Neuroradiology (ASNR), Canadian Society of Neuroradiology (CSNR), European Society of Minimally Invasive Neurological Therapy (ESMINT), European Society of Neuroradiology (ESNR), European Stroke Organization (ESO), Japanese Society for NeuroEndovascular Therapy (JSNET), The French Society of Neuroradiology (SFNR), Ibero-Latin American Society of Diagnostic and Therapeutic Neuroradiology (SILAN), Society of NeuroInterventional Surgery (SNIS), Society of Vascular and Interventional Neurology (SVIN), World Stroke Organization (WSO), World Federation of Interventional Neuroradiology (WFITN). Standards of practice in acute ischemic stroke intervention: international recommendations. J Neurointerv Surg 2018;10:1121-26 CrossRef Medline

15. Fiorelli M, Bastianello S, von KR, et al. Hemorrhagic transformation within 36 hours of a cerebral infarct: relationships with early clinical deterioration and 3-month outcome in the European Cooperative Acute Stroke Study I (ECASS I) cohort. Stroke 1999; 30:2280-84 CrossRef Medline

16. Suh SH, Cloft HJ, Fugate JE, et al. Clarifying differences among thrombolysis in cerebral infarction scale variants: is the artery half open or half closed? Stroke 2013;44:1166-68 CrossRef Medline
17. Lee SJ, Hong JM, Lee M, et al. Cerebral arterial calcification is an imaging prognostic marker for revascularization treatment of acute middle cerebral arterial occlusion. J Stroke 2015;17:67-75 CrossRef Medline

18. Mokin M, Morr S, Natarajan SK, et al. Thrombus density predicts successful recanalization with Solitaire stent retriever thrombectomy in acute ischemic stroke. J Neurointerv Surg 2015;7:104-07 CrossRef Medline

19. Brinjikji W, Duffy S, Burrows A, et al. Correlation of imaging and histopathology of thrombi in acute ischemic stroke with etiology and outcome: a systematic review. J Neurointerv Surg 2017;9:529-34 CrossRef Medline

20. Berkhemer OA, Fransen PSS, Beumer D, et al; MR CLEAN Investigators. A randomized trial of intraarterial treatment for acute ischemic stroke. N Engl J Med 2015;372:11-20 CrossRef Medline

21. Goyal M, Menon BK, van Zwam WH, et al; HERMES Collaborators. Endovascular thrombectomy after large-vessel ischaemic stroke: a meta-analysis of individual patient data from five randomised trials. Lancet 2016;387:1723-31 CrossRef Medline

22. Hesse AC, Behme D, Kemmling A, et al. Comparing different thrombectomy techniques in five large-volume centers: a 'real world' observational study. J Neurointerv Surg 2018;10:525-29 CrossRef Medline

23. Binning MJ, Bartolini B, Baxter B, et al. Trevo 2000: results of a large real-world registry for stent retriever for acute ischemic stroke. $J$ Am Heart Assoc 2018;7:e010867 CrossRef Medline

24. Gunning GM, McArdle K, Mirza M, et al. Clot friction variation with fibrin content: implications for resistance to thrombectomy. $J$ Neurointerv Surg 2018;10:34-38 CrossRef Medline

25. Chang Y, Kim BM, Bang OY, et al. Rescue stenting for failed mechanical thrombectomy in acute ischemic stroke: a multicenter experience. Stroke 2018;49:958-64 CrossRef Medline

26. Wareham J, Flood R, Phan K, et al. A systematic review and metaanalysis of observational evidence for the use of bailout self-expandable stents following failed anterior circulation stroke thrombectomy. J Neurointerv Surg 2019;11:675-82 CrossRef Medline

27. Sung SM, Lee TH, Cho HJ, et al. Recanalization with Wingspan stent for acute middle cerebral artery occlusion in failure or contraindication to intravenous thrombolysis: a feasibility study. AJNR Am J Neuroradiol 2012;33:1156-61 CrossRef Medline

28. Dumont TM, Natarajan SK, Eller JL, et al. Primary stenting for acute ischemic stroke using the Enterprise vascular reconstruction device: early results. J Neurointerv Surg 2014;6:36372 CrossRef Medline

29. Mocco J, Hanel RA, Sharma J, et al. Use of a vascular reconstruction device to salvage acute ischemic occlusions refractory to traditional endovascular recanalization methods. J Neurosurg 2010;112: 557-62 CrossRef Medline

30. Broussalis E, Weymayr F, Hitzl W, et al. Endovascular mechanical recanalization of acute ischaemic stroke in octogenarians. Eur Radiol 2016;26:1742-50 CrossRef Medline

31. Slater LA, Coutinho JM, Gralla J, et al; STAR and SWIFT investigators. TICI and age: what's the score? AJNR Am J Neuroradiol 2016;37:838-43 CrossRef Medline

32. Hilditch CA, Nicholson P, Murad MH, et al. Endovascular management of acute stroke in the elderly: a systematic review and metaanalysis. AJNR Am J Neuroradiol 2018;39:887-91 CrossRef Medline

33. Kirchhof K, Sikinger M, Welzel T, et al. Does the result of thrombolysis with recombinant tissue-type plasminogen activator (rt-PA) in rabbits depend on the erythrocyte- and fibrin-content of a thrombus? [in German] Rofo 2004;176:98-105 CrossRef Medline

34. Kissela BM, Kothari RU, Tomsick TA, et al. Embolization of calcific thrombi after tissue plasminogen activator treatment. J Stroke Cerebrovasc Dis 2001;10:135-38 CrossRef Medline 